J Res Dentomaxillofac Sci

JRDM://www.jrdms.dentaliau.ac.ir Journal of Research in Dental and Maxillofacial Sciences

\title{
Treatment Effects of Farmand Functional Appliance on Class II Division 1 Malocclusion
}

\author{
Pakshir $\mathbf{H}^{1}$, Mokhtar $\mathbf{A}^{2}$, Darnahal $\mathbf{A}^{3}$, Kamali $\mathbf{Z}^{4}$, Jamilian $\mathbf{A}^{5 *}$ \\ ${ }^{1}$ Professor, Orthodontic Research Center, Dental Faculty University of Medical Sciences, Shiraz, Iran. \\ ${ }^{2}$ Post Graduate Student, Orthodontics Dept,Dental Branch of Tehran, Islamic Azad University, Tehran, Iran. \\ ${ }^{3}$ Dentist. \\ ${ }^{4}$ MSc National Nutrition and Food Technology Research Institute, Faculty of Nutrition Sciences and Food Technology, Shahid Beheshti University \\ of Medical Sciences, Tehran, Iran. \\ ${ }^{5}$ Professor, Fellow of Orthognathic Surgery, Orthodontics Dept, Member of Craniomaxillofacial Research Center, Islamic Azad University, Tehran, \\ Iran.
}

\begin{tabular}{l}
\hline ARTICLE INFO \\
\hline Article Type \\
Orginal Article \\
\hline Article History \\
Received: April 2015 \\
Accepted: August 2015 \\
ePublished: Junuary 2016
\end{tabular}

Keywords:

Class II Division 1 malocclusion

Functional orthodontic appliance

Farmand

\section{ABSTRACT}

Background and Aim: The aim of the present study was to evaluate the cephalometric changes in Class II division 1 mandibular deficient patients treated with Farmand functional appliance.

Methods and Materials: Twenty-seven subjects (17 girls and 10 boys) with the mean age of $11.1 \pm 1.4$ years were involved in the present study. All the subjects were treated with Farmand functional appliance. Paired t-test and Wilcoxon test were used to evaluate the data. The significance level was set at $\mathrm{P}<0.005$.

Results: A skeletal Class I relationship and a marked reduction in the overjet were achieved with the use of Farmand appliance. ANB decreased significantly by $3.2 \pm 1.7$ degrees, while SNB increased from $74.3 \pm 1.7$ degrees to $77.6 \pm 2.3$ degrees $(\mathrm{P}<0.001)$. Conclusion: The results showed that Farmand functional appliance is effective in the treatment of mandibular deficiency in patients with Class II division 1 malocclusion.

\author{
Please cite this paper as: \\ Pakshir H, Mokhtar A, Darnahal A, Kamali Z, Jamilian A. Treatment \\ Effects of Farmand Functional Appliance on Class II Division 1 Maloc- \\ clusion J Res Dentomaxillofac Sci.2016;1(1):22-27.
}




\section{Introduction:}

A Class II malocclusion may result from mandibular deficiency, maxillary excess or a combination of both. However, the most common finding is skeletal mandibular retrusion. ${ }^{(1,2)}$ Approximately $15 \%$ of American children have Class II malocclusion; nevertheless, It seems that Class II problems are most prevalent in Caucasians of Northern European descent (for instance, 25\% of children in Denmark are reported to be Class II). ${ }^{(3)}$ Different removable functional appliances such as Activator, Bionator, Fränkel-2, Herbst, R-appliance, and Twin Block have been used to treat Class II division 1 malocclusion and mandibular deficiency. ${ }^{(4-12)}$ Functional appliances put the mandible in a forward position and result in stretches of the related attached muscular groups of the mandible, which create bone remodeling and muscular adaptation. Investigators have also proposed that class II correction observed with functional appliances was the result of headgear effect on the nasomaxillary growth. ${ }^{(13)}$

One of the functional appliances used for the correction of mandibular deficiency is "Farmand Appliance". ${ }^{(14)}$ It has been shown that this appliance causes significant changes in the position and anterior displacement of the Hyoid bone, resulting in improved airway and respiratory status of the patients. ${ }^{(14)}$

An electronic search in the literature shows that very few studies have evaluated the treatment effects of Farmand appliance; therefore, the aim of this study was to assess the dentoskeletal effects of Farmand appliance on prepubertal patients with Class II division 1 malocclusion and mandibular deficiency.

\section{Methods and Materials:}

Twenty-seven subjects (17 girls and 10 boys) were selected from among the individuals who were treated with Farmand appliance. The mean age of the patients was $11.1 \pm 1.4$ years. All the patients and their parents were informed of the study procedures, and they signed an informed consent. The procedures were carried out according to the criteria of the local Ethics Commission and the Helsinki Declaration.
At the beginning of the treatment, (Figures 1 and 2) all the patients were in prepubertal stage (CS1 and CS2), according to the recently improved version of cervical vertebral maturation (CVM) method described by Franchi et al15 and Baccetti et al.16

All the subjects met the following inclusion criteria:

1- $\mathrm{ANB}>5^{\circ}, \mathrm{SNB}<77^{\circ}$, overjet $>5 \mathrm{~mm}$ on the initial lateral cephalograms

2- No syndromic or medically compromised patients;

3- No previous surgical intervention;

4- No use of other appliances before or during the period of functional treatment.

5- A normal mandibular growth pattern; neither horizontal nor vertical growers.

6- No skeletal asymmetry

The patients were instructed to wear the appliance full-time except for eating, contact sports and tooth brushing. The average treatment time was $16 \pm 1.7$ months. (Figures 3 and 4 )

Farmand appliance is a passive tooth borne appliance. It consists of two extended labial bows, a tongue bow, two rests (stops), and an acrylic plate. The acrylic plate extends form the occlusal surface to the lingual shields. A heavy wire (with $1 \mathrm{~mm}$ diameter), which acts as a tongue bow, is positioned posteriorly to connect the right and left acrylic parts on the palatal aspect in order to reinforce the appliance. Upper and lower labial bows are constructed of $0.7 \mathrm{~mm}$ stainless steel wire extended from canine to canine with horizontal loops in the canine region. The rests (stops) are placed on the mesial surface of upper and lower first molars. The construction bites were taken with the upper and lower anterior teeth in an edge to edge occlusion with 2 to 3 $\mathrm{mm}$ posterior clearance. Lateral cephalograms were taken in centric occlusion at the start (T1) (Figure 5) and at the completion (T2) (Figure 6) of the functional treatment. Each film was traced by one investigator on 0.003 -inch frosted acetate with a $0.3 \mathrm{~mm}$ lead pencil and was checked by another investigator to verify the accuracy of the anatomical landmark detection. Images of the bilateral structures were bisected. 


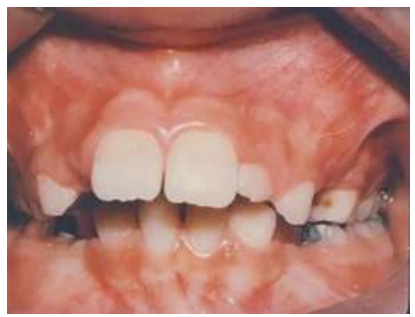

Figure 1- Pretreatment intra oral images

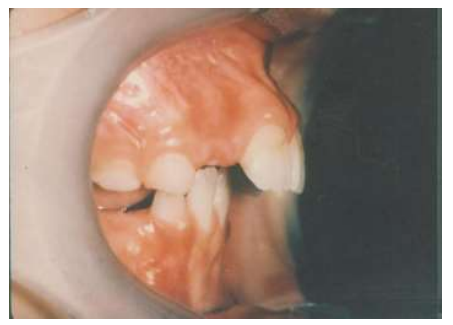

Figure 2- Pretreatment intra oral images

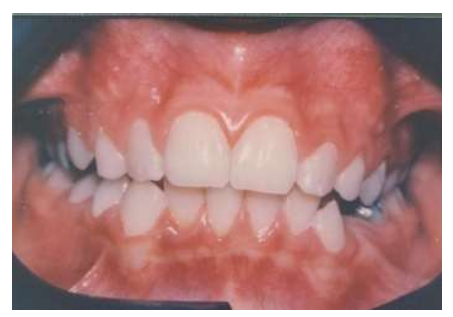

Figure 3- Post treatment intra oral images

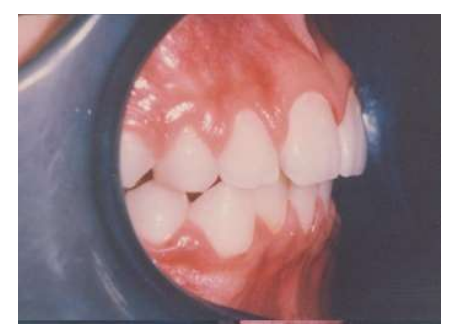

Figure 4- Post treatment intra oral images

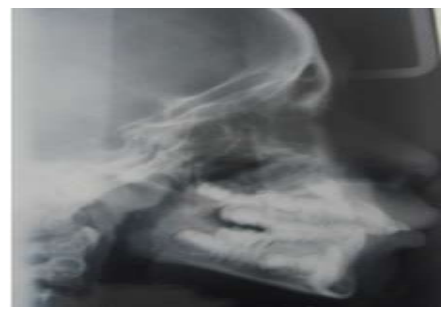

Figure 5- Pretreatment cephalometric image

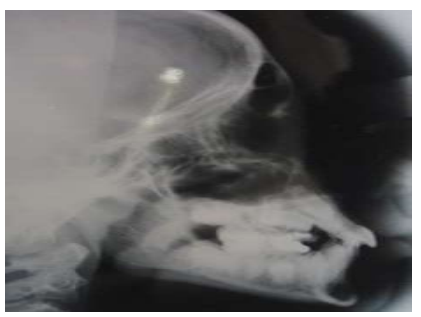

Figure 6- Pretreatment cephalometric image

Disagreements were resolved by retracing the landmark or the structure to the satisfaction of both observers.

The SNA, SNB, ANB, Witts (connecting points $A$ and $B$ perpendicular to the occlusal plane), GoGn (the distance between gonion and gnathion, representing the mandibular length), CoGn (the distance from condyle to gnathion), Co-Pog (the distance from condyle to pogonion), overjet, Jarabak index (the ratio between posterior and anterior facial heights; $\mathrm{S}-\mathrm{Go} / \mathrm{N}-\mathrm{Me}$ ), GoGn-Sn (the angle between SN and the mandibular plane), Palatal-GoGn (the angle between the palatal and mandibular planes), facial angle (the angle formed by the intersection of the Frankfort plane with the nasion-pogonion line), U1 to SN (the angle between the long axis of upper central incisor and the anterior cranial base), IMPA (the angle between the long axis of lower central incisor and the mandibular plane), and interincisal angle (the angle between the upper and lower incisors) were measured on $\mathrm{T} 1$, and $\mathrm{T} 2$ radiographs.

The reliability of the measurements was determined by randomly selecting 10 cephalograms at the beginning and at the end of the treatment. These cephalograms were re-measured by 2 other blinded investigators. The method error was calculated using Dahlberg's formula17. Values 
of error in the present study ranged from 0.21 to 0.64 , indicating that there was a good reliability of the measurements.

The magnification factor of the cephalograms was standardized at $8 \%$. The Statistical Package for Social Sciences, Version 20 (SPSS Inc. Chicago, Illinois, USA) was used to analyze the data. Kolmogorov-Smirnov normality test was applied to the cephalometric data. Paired T-test was used for evaluations if the distribution was normal; otherwise, Wilcoxon test was applied. Statistical significance was set at $\mathrm{P}<0.005$.

\section{Results:}

Paired T-test showed that the SNA decreased from $81.2 \pm 1.5$ degrees to $81.4 \pm 1.3$ degrees $(\mathrm{P}<0.124)$; while, the SNB significantly increased from $74.3 \pm 1.7$ degrees to $77.6 \pm 2.3$ degrees. The ANB decreased by $3.2 \pm 1.7$ degrees $(\mathrm{P}<0.617)$. Upper 1 to $\mathrm{SN}$ decreased significantly from $110.1 \pm 7$ degrees to $104.4 \pm 5.7$ degrees; while, The IMPA increased by $6.2 \pm 3.8$ degrees $(\mathrm{P}<0.001)$. The GoGn increased from $66.5 \pm 3.5$ $\mathrm{mm}$ to $69.2 \pm 3.5 \mathrm{~mm}(\mathrm{P}<0.001)$. Tables 1 and 2 show the pre and post-treatment values.

Table 1- Pre and post treatment values

\begin{tabular}{|c|c|c|c|c|c|c|}
\hline \multirow{2}{*}{ Variables } & & \multicolumn{2}{|c|}{ Before } & \multicolumn{2}{|c|}{ After } & \multirow{2}{*}{ P-value } \\
\hline & & Mean & SD & Mean & SD & \\
\hline \multirow[t]{8}{*}{ Sagittal } & SNA $\left({ }^{\circ}\right)$ & 81.2 & 1.5 & 81.4 & 1.3 & 0.124 \\
\hline & $\operatorname{SNB}\left({ }^{\circ}\right)$ & 74.3 & 1.7 & 77.6 & 2.3 & $0.001 *$ \\
\hline & ANB $\left(^{\circ}\right)$ & 6.8 & 1.6 & 3.6 & 2.3 & $0.001 *$ \\
\hline & Witts (mm) & 4.2 & 1.6 & 1.9 & 1.7 & $0.001 *$ \\
\hline & GoGn (mm) & 66.5 & 3.5 & 69.2 & 3.5 & $0.001 *$ \\
\hline & Co-Gn & 103.7 & 2.9 & 106.2 & 2.6 & $0.001 *$ \\
\hline & Co-Pog & 101.8 & 1.6 & 106.3 & 1.8 & $0.001 *$ \\
\hline & Overjet & 7.1 & 2.1 & 3.6 & 1.9 & $0.001 *$ \\
\hline \multirow[t]{5}{*}{ Vertical } & Jarabak (\%) & 64.1 & 2.2 & 62 & 1.4 & $0.001 *$ \\
\hline & GoGn-Sn & 31.8 & 4.2 & 34.1 & 4 & $0.001 *$ \\
\hline & Palatal- & 25.3 & 2.6 & 27.5 & 1.9 & $0.001 *$ \\
\hline & Facial & 82.9 & 2.6 & 85.1 & 2.5 & $0.001^{*}$ \\
\hline & Gonial & 123.7 & 3 & 128.7 & 2.1 & $0.001 *$ \\
\hline \multirow[t]{3}{*}{ Dental } & $\mathrm{U} 1-\mathrm{Sn}\left(^{\circ}\right)$ & 110.1 & 7 & 104.4 & 5.7 & $0.001 *$ \\
\hline & $\operatorname{IMPA}\left({ }^{\circ}\right)$ & 95.7 & 7.3 & 101.9 & 6.6 & $0.001 *$ \\
\hline & Interincisal & 117.8 & 5.5 & 118 & 6.7 & 0.777 \\
\hline
\end{tabular}


Table 2- Changes of the cephalometric data

\begin{tabular}{clcc}
\multirow{2}{*}{ Variables } & \multicolumn{2}{c}{ Farmand } \\
\cline { 2 - 4 } & & Mean & SD \\
\hline \multirow{5}{*}{ SNA $\left(^{\circ}\right)$} & 0.2 & 0.7 \\
\cline { 2 - 4 } & SNB $\left(^{\circ}\right)$ & 3.3 & 1.9 \\
\cline { 2 - 4 } & ANB $\left(^{\circ}\right)$ & -3.2 & 1.7 \\
\cline { 2 - 4 } & Witts $(\mathrm{mm})$ & -2.3 & 1.5 \\
\cline { 2 - 4 } & GoGn $(\mathrm{mm})$ & 2.7 & 1.5 \\
\cline { 2 - 4 } & Co-Gn $(\mathrm{mm})$ & 2.6 & 1.2 \\
\cline { 2 - 4 } & Co-Pog $(\mathrm{mm})$ & 4.5 & 1.9 \\
\cline { 2 - 4 } Vertical & Overjet $(\mathrm{mm})$ & -3.5 & 2.3 \\
\hline & Jarabak $(\%)$ & -2.1 & 1.8 \\
\cline { 2 - 4 } & GoGn-Sn $\left({ }^{\circ}\right)$ & 2.3 & 1.8 \\
\cline { 2 - 4 } & Palatal-GoGn & 2.2 & 2.1 \\
\cline { 2 - 4 } & Facial Angle & 2.2 & 1.2 \\
\cline { 2 - 4 } & Gonial Angle & 4.9 & 3 \\
\hline \multirow{3}{*}{ Dental } & U1-Sn $\left({ }^{\circ}\right)$ & -5.7 & 4.2 \\
\cline { 2 - 4 } & IMPA $\left(^{\circ}\right)$ & 6.2 & 3.8 \\
\cline { 2 - 4 } & Inter-incisal & 0.3 & 4.7 \\
& Angle $\left(^{\circ}\right)$ & & \\
\hline
\end{tabular}

\section{Discussion:}

The treatment methods for Class II Division 1 malocclusion have been abundantly reported in the literature. Treatment can include extra oral headgear, removable or fixed functional appliances, and maxillary molar distalization appliances, followed by anterior retraction. It can be camouflaged by the extraction of maxillary premolars to eliminate the overjet by establishing a Class II molar relationship. ${ }^{(18,19)}$

The findings of the present study showed that, Farmand appliance could successfully improve the intermaxillary discrepancy in Class II growing patients with mandibular deficiency. After treatment, the SNB and ANB showed significant changes. The Increased SNB and decreased ANB are the indicators of satisfactory changes in the mandibular growth. The increase in the GoGn, Co-Gn, and Co-Pog also indicates positive mandibular growth.

Farmand appliance is a passive tooth-borne appliance, composed of one extended labial bow on each jaw, two rests (stops) on each dental arch, a tongue bow and an acrylic plate. The labial bows with a distance of $1 \mathrm{~mm}$ from the labial surfaces of upper and lower anterior teeth, act as an eruptive guidance for the incisors and eliminate the forces of the perioral muscles, especially in the cases of severe contractions of the Mentalis muscle. The tongue bow with the distally-directed loops, helps the patient to redirect his/her tongue to a distal position, thus removing the tongue pressure from the anterior part of the upper jaw. In addition, the patient is instructed to open and close his/her mandible while stabilizing the appliance on the maxillary arch by the tip of his/her tongue. This kind of exercise will improve the patient's adaptation with the new advanced mandibular position. The rests (stops), which are placed on the mesial surfaces of the first molars, restrict the mesial movements of the mentioned teeth, and assist in achieving a Class I molar relationship by forward movement of the mandible. Treatment success has been defined as an improvement in molar relationship of at least a half to three-quarters cusp width, depending on whether or not the leeway space was used during treatment. One of the factors that influenced treatment success in the present study was the level of cooperation of the patients which was influenced by the small size of Farmand appliance.

In two recent studies, Yassaei and Soroush 14 and Yassaei et al 20 evaluated the effects of Farmand functional appliance on the position of Hyoid bone in patients with Class II division 1 malocclusion. They found that the Hyoid bone shifted significantly forwards in the horizontal dimension.

Farmand appliance, similar to Bionator appliance, is not as bulky as many other functional appliances, and shows a better patient tolerance and less interference with speech.

After skeletal correction, further treatments were continued with fixed orthodontics for all the patients involved in the present study.

\section{Conclusion:}

Farmand functional appliance can be successfully implemented in the correction of mandibular deficiency in patients with Class II division 1 malocclusion, and can be used as an alternative functional appliance. 


\section{Acknowledgments:}

The authors would like to thank Dental research center of Tehran university and The AFM center of Iran university of science and Technology for the laboratory work.

\section{Conflict of interests}

Authors report no conflict of interest related to this study.

\section{References:}

1.McNamara JA Jr, Ellis E 3rd. Cephalometric analysis of untreated adults with ideal facial and occlusal relationships. Int J Adult Orthodon Orthognath Surg 1988;3(4):221-31.

2. Perillo L, Padricelli G, Isola G, Femiano F, Chiodini P, Matarese G. Class II malocclusion division 1: a new classification method by cephalometric analysis. Eur J Paediatr Dent 2012;13(3):192-6.

3. Showkatbakhsh R, Castaldo MI, Jamilian A, Padricelli G, Fahimi Hanzayi M, Cappabianca S et al. Treatment effects of R-appliance and Frankel-2 in Class II division 1 malocclusions. Eur J Paediatr Dent 2013 ;14(1):17-22

4.O'Brien K, Wright J, Conboy F, Appelbe P, Davies L, Connolly I et al. Early treatment for Class II Division 1 malocclusion with the Twin-block appliance: a multi-center, randomized, controlled trial. Am J Orthod Dentofacial Orthop 2009;135(5):573-9.

5. Perillo L, Castaldo MI, Cannavale R, Longobardi A, Grassia V, Rullo R et al. Evaluation of long-term effects in patients treated with Frankel-2 appliance. Eur J Paediatr Dent $2011 ; 12(4): 261-6$.

6-Jamilian A, Showkatbakhsh R, Amiri SS. Treatment effects of the R-appliance and twin block in Class II division 1 malocclusion. Eur J Orthod 2011 Aug;33(4):354-8.

7. Pancherz H. The Herbst appliance: a paradigm change in Class II treatment. World J Orthod 2005;6 Suppl:8-10.

8. Franchi L, Pavoni C, Faltin KJr., McNamara JA Jr , Cozza P. Long-term skeletal and dental effects and treatment timing for functional appliances in Class II malocclusion 2013;83(2):334-40.

9. Perillo L, Johnston LE Jr, Ferro A. Permanence of skeletal changes after function regulator (FR-2) treatment of patients with retrusive Class II malocclusions. Am J Orthod Dentofacial Orthop 1996;109(2):132-9.

10. Showkatbakhsh R, Meybodi SE, Jamilian A, Meybodi SA, Meybodi EM. Treatment effects of R-appliance and anterior inclined bite plate in class II, division I malocclusion. J Appl Oral Sci 2011;19(6):634-8.

11. Jamilian A, Showkatbakhsh R, Kamali Z. R-appliance: a different design in functional therapy in Class
II Division I malocclusion. Int J Orthod Milwaukee 2009;20(2):11-4.

12. Hagglund P, Segerdal S. An improved version of the integrated Herbst appliance. J Clin Orthod 2010;44(3):190-5.

13. Yassaei S, Sorush M. Changes in hyoid position following treatment of Class II division1 malocclusions with a functional appliance. J Clin Pediatr Dent $2008 ; 33(1): 81-4$.

14. Franchi L, Baccetti T, De Toffol L, Polimeni A, Cozza P. Phases of the dentition for the assessment of skeletal maturity: a diagnostic performance study. Am J Orthod Dentofacial Orthop 2008;133(3):395-400.

15.Baccetti T, Franchi L, McNamara JA, Jr. The cervical vertebral maturation (CVM) method for assessment of optimal treatment timing in dentofacial orthopedics. Seminars in Orthodontics 2005;(11):119-29.

16.Dahlberg G. Statistical methods for medical and biological students. Br Med J 1940 14; 2(4158):358-9. 17. Kurosawa M, Ando K, Goto S. Class II Division 1 malocclusion with a high mandibular plane angle corrected with 2-phase treatment. Am J Orthod Dentofacial Orthop 2009;135(2):241-51.

18. Chung KR, Kim SH, Mo SS, Kook YA, Kang SG. Severe Class II division 1 malocclusion treated by orthodontic miniplate with tube. Prog Orthod 2005; 6(2):172-86.

19. Yassaei S, Jamilian A, Joshan N. Effects of TwinBlock and Faramand-LL appliances on soft tissue profile in the treatment of Class II division 1 malocclusion. Int J Orthod Milwaukee 2014 ;25(4):57-62. 